\title{
Imunossupressão com Ciclofosfamida e Fludarabina, com Suporte de Células Tronco Hematopoéticas Autólogas CD-34+, para Tratamento de Esclerose Sistêmica Severa ${ }^{(*)}$
}

\section{Immunosuppression with Cyclophosphamide and Fludarabine, with Support of Autologous CD-34 + Stem Cells, in the Treatment of Severe Scleroderma}

\author{
Carlos Alberto von Mühlen ${ }^{(1)}$,Éverton Luís Hinterholz ${ }^{(2)}$, Bernardo Garicochea ${ }^{(3)}$, Pedro Weingrill(4), Carlos \\ Barrios $^{(5)}$, Mário Sérgio Fernandes ${ }^{(6)}$, Rosângela Dahmer ${ }^{(2)}$, Mauro W. Keiserman ${ }^{(7)}$ e Henrique Luiz Staub ${ }^{(8)}$
}

\section{RESUMO}

Evidências recentes mostram a possibilidade de se retardar a evolução da esclerose sistêmica (ES), mesmo em suas formas mais graves, com ablação de células $\mathrm{T}$, no momento reconhecidas como as principais envolvidas no processo fisiopatogênico. Altas doses de quimioterapia com suporte de células tronco hematopoéticas (CTH) - às vezes denominado pela literatura de "transplante da medula óssea" - tem-se mostrado um meio efetivo de controlar algumas doenças auto-imunes, entre elas a esclerose sistêmica. Neste trabalho é relatado o caso de paciente com forma difusa de esclerose sistêmica, em que se efetuou imunossupressão com ciclofosfamida $0,5 \mathrm{~g} / \mathrm{m}^{2}$ e fludarabina e suporte de células CD34+ autólogas sem depleção específica de linfócitos T. O paciente foi avaliado de forma periódica durante 12 meses através de testes cutâneos, exames de imagem, exames laboratoriais e questionário sobre qualidade de vida. A evolução imediata mostrou melhora importante dos quadros cutâneo e gastrointestinal, com melhora da diarréia e síndrome de má-absorção, que no entanto não se manteve após seis meses de evolução. O paciente apresentou reação transfusional passageira, infecção por herpes zoster e broncopneumonia durante o período de observação, evoluindo para óbito 12 meses após o procedimento. Este ocorreu por complicações no trato intestinal e broncopneumonia por aspiração. Imunossu-

\begin{abstract}
Immune ablation of $T$ lymphocytes, key players in the physiopathogenic processes leading to autoimmune diseases, may arrest scleroderma progression even in some severely ill patients. High-dose chemotherapy followed by autologous stem cell reinfusion - sometimes named peripheral blood stem cell transplantation - has been an effective therapy for some autoimmune diseases, including scleroderma. In this paper the authors present a patient with the diffuse form of scleroderma who received immunosuppression with cyclophosphamide $0.5 \mathrm{~g} / \mathrm{m}^{2}$ and fludarabine followed by infusion of autologous CD-34+ cells without $T$ lymphocyte purging. This patient was followed up with cutaneous score measures, imaging and laboratory tests, as well as a well-being questionnaire. After transplantation there were major positive responses on skin and gastrointestinal tract, with cessation of diarrhea and malabsorption syndrome. These clinical improvements did not last past 6 months. We observed transitory stem cell transfusion reaction and localized herpes zoster. The patient died 12 months after the procedure due to aspirative pneumonia and gastrointestinal complications. The immunosuppressive regimen, and not the autologous stem cell
\end{abstract}

\footnotetext{
* Serviços de reumatologia, oncologia e hematologia do Hospital São Lucas da Faculdade de Medicina da Pontifícia Universidade Católica do Rio Grande do Sul (PUCRS), Porto Alegre, RS. Trabalho realizado com o apoio do Fundo de Auxílio à Pesquisa e Ensino em Reumatologia da Sociedade Brasileira de Reumatologia. Recebido em 21/2/2002. Aprovado, após revisão, em 27/11/2003.

1. Professor titular de reumatologia e imunologia da Faculdade de Medicina da PUCRS.

2. Médico(a) residente do serviço de reumatologia do Hospital São Lucas da PUCRS.

3. Professor adjunto de hematologia da Faculdade de Medicina da PUCRS, chefe do serviço de oncologia do Hospital São Lucas da PUCRS.

4. Médico preceptor de reumatologista do Hospital São José e professor da Faculdade de Medicina da Universidade de Joinville, SC.

5. Professor assistente de oncologia da Faculdade de Medicina da PUCRS.

6. Professor assistente de hematologia da Faculdade de Medicina da PUCRS.

7. Chefe do serviço de reumatologia do Hospital São Lucas da PUCRS.

8. Professor assistente de reumatologia da Faculdade de Medicina da PUCRS.
}

Endereço para correspondência: Carlos Alberto von Mühlen. R. Cel.Camisão 132, ap. 201, Porto Alegre, RS, CEP 90540-050. E-mail: cavm@rocketmail.com 
pressão induzida por drogas, e não o transplante autólogo de células CD-34+, pode ter sido o mecanismo responsável pela melhora nos primeiros meses de observação.

Palavras-chave: esclerose sistêmica, doenças auto-imunes, imunossupressão, transplante autólogo, células CD-34+.

\section{INTRODUÇÃO}

A esclerose sistêmica (ES) em sua forma difusa possui pior prognóstico se comparada à forma CREST. Seu tratamento é motivo de controvérsia, principalmente por desconhecimento fisiopatogênico. Estudos retrospectivos mostram que a D-Penicilamina aumenta a sobrevida dos pacientes em cinco anos, quando comparados com indivíduos sem tratamento $^{(1-2)}$, com melhora clínica maior sendo observada nos acometimentos cutâneo e pulmonar. Inúmeros outros fármacos foram propostos, sem no entanto trazer um diferencial importante nos resultados de fatores clínicos como medidas do acometimento sistêmico. A exceção talvez possa ser creditada à utilização de pulsoterapia mensal com altas doses de ciclofosfamida via parenteral ${ }^{(3)}$. Mais recentemente alguns resultados se mostram promissores com o uso de imunossupressão seguida ou não de suporte com transplante autólogo de células hematopoéticas pluripotenciais (antes chamado "transplante de medula óssea"), como tratamento para esclerodermia e outras doenças auto-imunes de adultos e crianças com grave acometimento sistêmico ${ }^{(4-10)}$.

O objetivo deste trabalho é o de relatar o caso de um paciente com esclerodermia severa que recebeu imunossupressão com ciclofosfamida e fludarabina, seguido de suporte com CTH e manutenção com ciclofosfamida e fludarabina. Trata-se, na medida do nosso conhecimento, do primeiro caso a receber tal tratamento no Brasil.

\section{RELATO DO CASO}

Paciente masculino, branco, 46 anos, professor, procedente de Santa Catarina, previamente hígido, desde 1993 com fenômeno de Raynaud, artralgias em mãos e joelhos, fadiga e espessamento cutâneo de mãos e pés que em poucos meses evoluiu para face, tórax e abdome. $\mathrm{O}$ exame físico da época mostrava ausculta cardíaca e pulmonar sem anormalidades, diminuição da elasticidade e pregueamento da pele dos membros superiores, face e tronco com áreas de discromia cutânea (hipo e hiperpigmentação) e sinais de atrofia cutânea nos dedos das mãos já com certo grau de aderência a planos profundos. $\mathrm{O}$ paciente preenchia os transplantation, could have been responsible for the observed transitory patient improvement.

Keywords: systemic scleroderma, autoimmune diseases, immunosuppression, autologous stem cell transplantation, CD-34+ cells.

critérios de classificação do Colégio Americano de Reumatologia para esclerose sistêmica ${ }^{(11)}$.

As chapas contrastadas de esôfago mostravam hipoperistalse esofágica, com FAN reagente em título 1:160 de padrão pontilhado. Os demais exames - hemograma, creatinina, creatinafosfoquinase, comum de urina, radiografias de tórax e de mãos - não mostravam anormalidades. Iniciou-se uso de prednisona $10 \mathrm{mg} /$ dia, D-Penicilamina $300 \mathrm{mg} /$ dia (atingindo a dose de $900 \mathrm{mg} /$ dia em 4 meses), nifedipina $20 \mathrm{mg} /$ dia e ciclofosfamida $1 \mathrm{~g}$ endovenosa por mês durante 6 meses.

Houve melhora subjetiva do fenômeno de Raynaud, porém persistiu o quadro de espessamento cutâneo, o qual se tornou generalizado. Em 1995 o paciente apresentou epigastralgia, realizando novos exames laboratoriais e de imagem. A tomografia computadorizada de tórax evidenciou formações bolhosas em ápices e infiltrado intersticial na base direita. A endoscopia digestiva alta mostrou esofagite e pangastrite. Demais exames como hemograma, creatinina, transaminases, comum de urina e radiografias do tórax foram novamente normais.

Foi suspensa a D-Penicilamina em conseqüência do quadro digestivo, havendo piora marcada do quadro cutâneo após alguns poucos meses. Foi reiniciada a ciclofosfamida na dose de $600 \mathrm{mg}$ endovenosa mensal, porém tendo que ser suspensa pois o paciente apresentou intensa astenia. Neste período houve melhora das úlceras digitais. Em 1998 o paciente teve quadro de mialgias, fraqueza muscular, com alterações laboratoriais sugestivas de miopatia $(\mathrm{CPK}=1717$ $\mathrm{mg} / \mathrm{dl}$, normal até 170 ; e TGO $=120 \mathrm{mg} / \mathrm{dl}$, normal até 20), com piora dos sintomas digestivos: dor epigástrica, alguns episódios de vômitos, distensão abdominal, alternância de diarréia (três episódios ao dia) com constipação e marcada perda de peso. Neste período aumentou-se a dose de prednisona para $40 \mathrm{mg} /$ dia. Houve boa resposta da miopatia com melhora da fraqueza muscular e normalização da CPK. Reduziu-se a prednisona de forma gradativa até sua suspensão e iniciou-se com bloqueadores da bomba de prótons, drogas pró-cinéticas e metronidazol $400 \mathrm{mg} /$ dia. Houve piora progressiva do quadro intestinal, com intensificação da diarréia, dor abdominal difusa e emagrecimento de $8 \mathrm{~kg}$ em 6 meses, sem melhora com medicação proposta. 
O paciente foi então internado no Hospital São Lucas da Pontifícia Universidade Católica do Rio Grande do Sul (PUCRS), em Porto Alegre, RS, com o objetivo de realizar imunossupressão com ciclofosfamida e fludarabina e suporte de CTH para controle de sua doença. Neste período apresentava-se emagrecido, desidratado, com espessamento cutâneo generalizado e com vasculite de polpas digitais (Figura 1). A ausculta pulmonar apresentava ruídos bibasais compatíveis com fibrose pulmonar, o abdome estava distendido, porém sem defesa à palpação. $\mathrm{O}$ trânsito intestinal visto em chapas radiográficas mostrava dilatação de alças e alterações compatíveis com má absorção intestinal. Outros exames realizados nesta fase podem ser vistos na Tabela 1. Após estabilização clínica e consentimento informado do paciente foi iniciada antibioticoterapia profilática com fluconazol, sulfametoxazol com trimetoprim e aciclovir, e realizada a mobilização de células progenitoras CD34+ com o uso IV de fator esti- mulador de colônia de granulócitos $300 \mathrm{mcg} /$ dia durante 6 dias. As células foram coletadas durante 3 dias e a contagem celular foi realizada por citometria de fluxo até que pelo menos $2 \times 10^{6}$ células CD34+/kg fossem obtidas. Não foi efetuada depleção de células T após coleta para não elevar o custo do procedimento e por dúvidas na literatura a respeito deste tipo de conduta ${ }^{(12,13)}$. Vários transplantes já foram efetuados com sucesso sem depleção de linfócitos $\mathrm{T}^{(14,15)}$. A embalagem com células CD34+ foi conservada a $-70^{\circ} \mathrm{C}$ até reinfusão. A seguir o paciente recebeu infusão IV de ciclofosfamida $500 \mathrm{mg} / \mathrm{m}^{2}$ e fludarabina $35 \mathrm{mg} / \mathrm{m}^{2}$ durante 3 dias consecutivos, seguidos da reinfusão de células progenitoras. Após, seguiu-se administração de $300 \mathrm{mcg} /$ dia de fator estimulador de colônia de granulócitos durante 11 dias. Nova imunossupressão com dose total de ciclofosfamida $500 \mathrm{mg} / \mathrm{m}^{2}$ e de fludarabina $35 \mathrm{mg} / \mathrm{m}^{2}$ de manutenção foi realizada 5 meses e 8 meses após o primeiro ciclo.
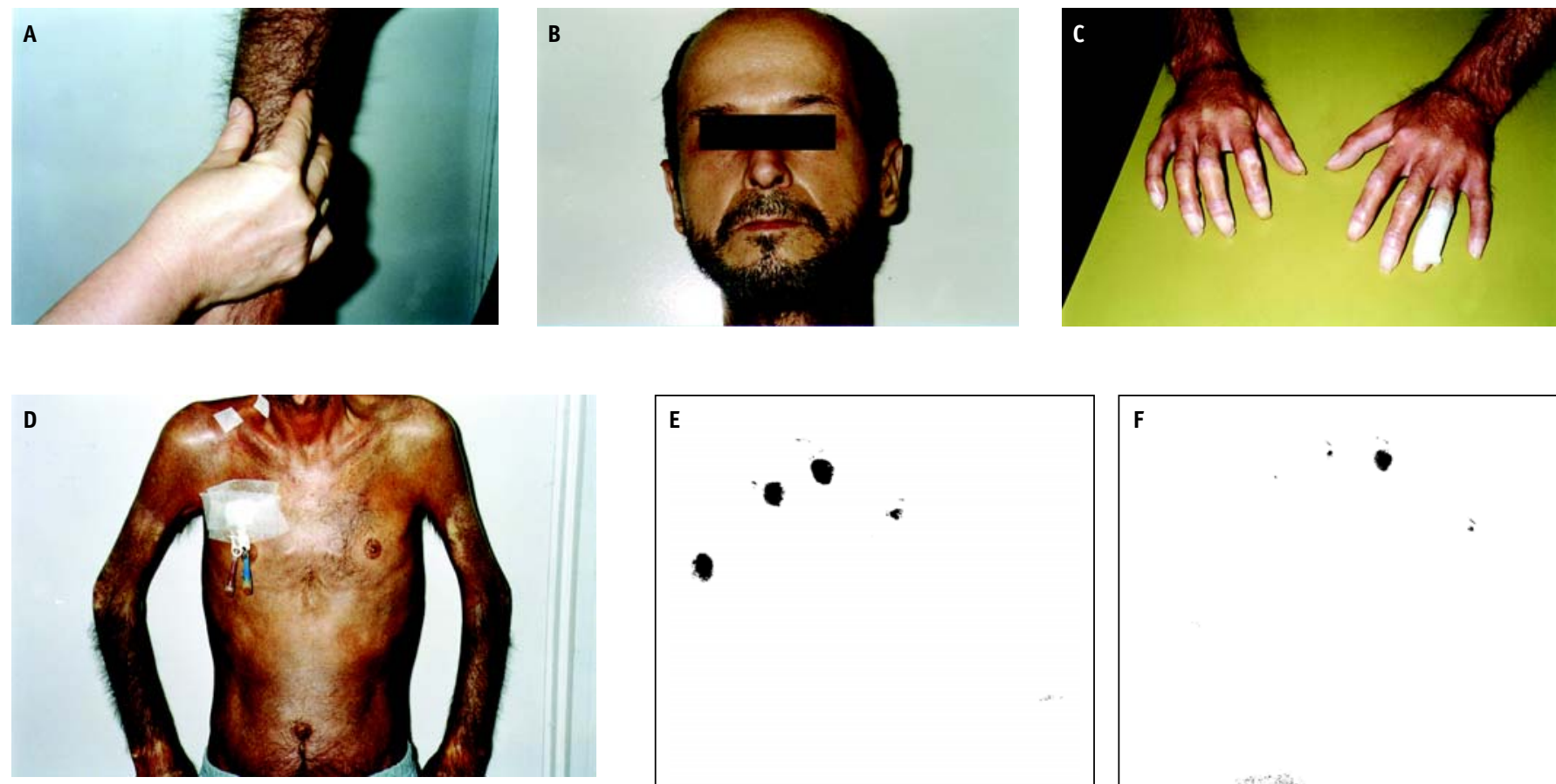

Figura 1 - A) Examinando a induração subcutânea de antebraço. B) Fácies do paciente, com diminuição de pregas cutâneas na fronte. C) Mãos com áreas discrômicas e vasculite ulcerada em dígito IV da mão esquerda. D) Visão geral do tórax e abdome, com áreas discrômicas, emaciação extrema. E) e F) Impressões palmares direita e esquerda, mostrando severo grau de esclerodactilia.
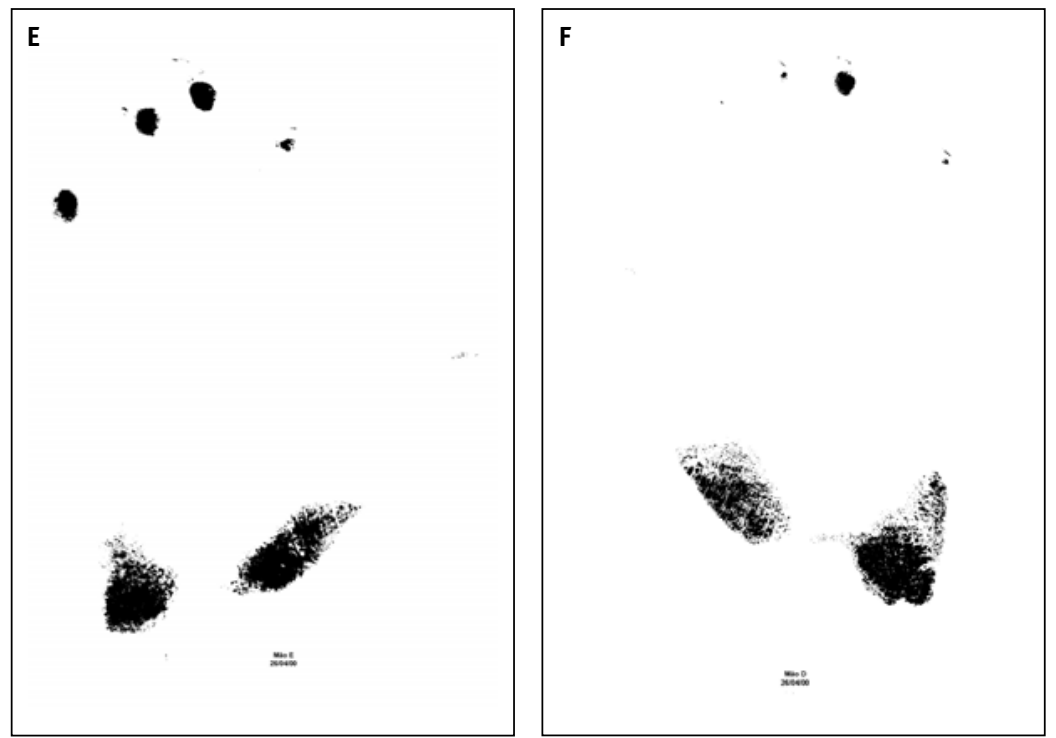
O paciente teve alta hospitalar 16 dias após o início da imunossupressão sem intercorrências graves. Apresentou durante a reinfusão de células $\mathrm{CD} 34+$ uma reação tipo distúrbio neurovegetativo, com calafrios, sensação de pânico e tremores, que cessaram espontaneamente em cerca de 30 minutos. O nadir de leucócitos no quarto dia após a imunossupressão foi de $5.700 / \mathrm{mm}^{3}$ e o de linfócitos de $57 / \mathrm{mm}^{3}$, não se atingindo, portanto, ablação total da medula óssea, o que ocorreu conforme programado. Medidas evolutivas de atividade da doença podem ser vistas na Tabela 1.

A tomografia computadorizada de tórax manteve o mesmo padrão de fibrose pulmonar bibasal. A impressão da abertura palmar não mostrou modificações. Os episódios de diarréia diminuíram para um episódio ao dia e as crises de dor e distensão abdominal tornaram-se bem mais brandas até cessar. O paciente seguiu com dieta pobre em fibras e rica em carnes brancas. Após a alta hospitalar seguiu tratamento com pentoxifilina $400 \mathrm{mg} / \mathrm{dia}$, usada pelas vasculites de polpas digitais, vibramicina $200 \mathrm{mg} / \mathrm{dia}$ (para a síndrome de má-absorção intestinal), omeprazol $20 \mathrm{mg} /$ dia (como profilático de lesões gastroduodenais), prednisona $15 \mathrm{mg}$ /dia e fluoxetina $20 \mathrm{mg} /$ dia (para depressão, após avaliação psiquiátrica).

Cerca de 3 meses após o transplante autólogo o paciente apresentou alguns episódios de crise hipertensiva sem perda de função renal onde foi iniciado o uso de captopril $50 \mathrm{mg} /$ dia. Neste período voltaram as crises de dor e distensão abdominal, porém de forma mais branda e fugazes, acompanhadas por um episódio de fezes amolecidas ao dia. O paciente realizou nova sessão de quimioterapia com $35 \mathrm{mg} / \mathrm{m}^{2}$ de fludarabina e $500 \mathrm{mg} / \mathrm{m}^{2}$ de ciclofosfamida 5 e 8 meses após o transplante. Três meses após o último ciclo de quimioterapia apresentou infecção por herpes zoster na região torácica, foi tratado com antiviral em doses usuais evoluindo bem, porém apresentou neuropatia pósherpética com boa resposta à amitriptilina.
Um mês após a infecção herpética apresentou quadro de pseudo-obstrução intestinal, provavelmente relacionada com sua doença de base, associado aos efeitos anticolinérgicos da amitriptilina. Foi tratado clinicamente e colocado em nutrição parenteral total, havendo melhora do quadro intestinal, evoluindo, porém, alguns dias após com quadro de infecção respiratória e plaquetopenia severa (contagem de 17.000 plaquetas $/ \mathrm{cm}^{3}$ ). Foi iniciada antibioticoterapia, aumentada a dose de prednisona para $2 \mathrm{mg} / \mathrm{kg} / \mathrm{dia}$ e efetuada infusão de imunoglobulinas IV $600 \mathrm{mg} / \mathrm{kg} / \mathrm{dia}$, sem que se obtivesse uma boa resposta da plaquetopenia. Esta apenas normalizou após melhora da infecção respiratória e a retirada do antibiótico. Apresentou então novo quadro de distensão abdominal com vômitos, tendo aspirado conteúdo gástrico e fazendo broncopneumonia aspirativa. Evoluiu para insuficiência respiratória intratável e óbito.

\section{DISCUSSÃO}

Os resultados obtidos com o tratamento imunossupressor seguido de infusão de células CD34+ autólogas mostraram boa recuperação do estado geral do paciente, com importante melhora das crises abdominais nos primeiros 5 meses de acompanhamento. Houve normalização do teste da D-Xylose, mostrando melhora marcada do padrão de absorção intestinal. A hemossedimentação caiu à metade, porém sem normalização (Tabela 1). Também o hematócrito tendeu à normalização após 5 meses, com nova queda aos 8 meses de evolução. Após melhora inicial da mobilidade das mãos e da pele como um todo, principalmente em termos subjetivos, não houve progressão favorável do quadro cutâneo com relação aos achados pré-transplante. Objetivamente não pudemos demonstrar melhora do escore cutâneo pela técnica de Kahaleh et al. ${ }^{(16)}$, ou da esclerodactilia pelo "carimbo" das mãos espalmadas. Piora progressiva dos sintomas gastrointestinais, marcantes neste paciente, ocorreu precocemente após o transplante.

TABELA 1

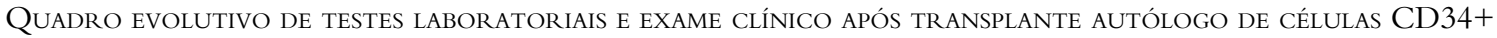

\begin{tabular}{lccccccc}
\hline Evolução & $\begin{array}{c}\text { VSG } \\
(\text { VR } \leq \mathbf{2 0})\end{array}$ & $\begin{array}{c}\text { Escore } \\
\text { cutâneo }\end{array}$ & $\begin{array}{c}\text { Pregas na } \\
\text { fronte }\end{array}$ & $\begin{array}{c}\text { Teste de D-Xilose } \\
(\mathbf{V R = 3 0 - 6 0 )}\end{array}$ & $\begin{array}{c}\text { Ht } \\
(\mathbf{\%})\end{array}$ & $\begin{array}{c}\text { Abertura oral } \\
(\mathbf{c m})\end{array}$ & $\begin{array}{c}\text { Creatinina (mg/dl) } \\
(\text { VR=0,6-1.2) }\end{array}$ \\
\hline Pré-TM0 & 84 & 55 & 5 & 12 & 26 & 4 & 0,5 \\
5 meses após & 46 & 54 & 6 & 50 & 34 & 4 & 0,5 \\
8 meses após & 81 & 54 & 6 & - & 29 & 4 & 0,9 \\
\hline Ht = hematócrito.
\end{tabular}


De fato, não seria de se esperar reversão de lesões esclerodérmicas estabelecidas na parede intestinal. O óbito após 12 meses do procedimento não se deveu a complicações atribuíveis diretamente à imunossupressão e reposição de células tronco $\mathrm{CD} 34+$, mas sim à pneumonia aspirativa e insuficiência respiratória complicada pela fibrose pulmonar.

O propósito do transplante autólogo de células CD$34+$ é permitir intensa imunossupressão com quase total imunoablação da medula óssea. Retiram-se assim as células $\mathrm{T}$ responsáveis potencialmente pela doença do indivíduo e se consegue uma reconstituição precoce dos elementos celulares do sangue, com menor risco ao paciente. As células pluripotenciais reinfundidas colonizarão a medula óssea, permitindo hematopoese precoce e um sistema imune novo.

Há na literatura vários estudos de pacientes com esclerodermia e outras doenças auto-imunes que receberam tratamento com imunossupressão e transplante autólogo de células progenitoras da medula óssea, em geral num tom positivo $^{(17,18)}$. Tyndall et al. ${ }^{(19)}$ realizaram, em 1997, imunoablação da medula óssea com ciclofosfamida seguida do transplante autólogo de medula óssea em uma paciente de 37 anos com esclerodermia grave, observando melhora no estado geral e redução do escore cutâneo em 6 meses de observação, achado semelhante ao de nosso paciente. Martini et al. ${ }^{(20)}$ observaram melhora sustentada após 2 anos de transplante autólogo e uso de anticorpo monoclonal CAMPATH-1G em jovem de 14 anos com esclerodermia. Em outro estudo, Breban et al. ${ }^{(21)}$ utilizaram $4 \mathrm{~g} / \mathrm{m}^{2}$ de ciclofosfamida seguidos da infusão de fator estimulador de colônia de granulócitos em 4 pacientes com artrite reumatóide severa e observaram diminuição da atividade da doença. Burt et al. ${ }^{(22)}$ efetuaram tratamento semelhante em 4 pacientes com artrite reumatóide refratária, mostrando boa tolerância e eficácia clínica em 2 casos, com diminuição do número de articulações inflamadas após 6 meses. Resultados aparentemente brilhantes também têm sido publicados em pacientes com lúpus eritematoso sistêmico e grave acometimento sistêmico ${ }^{(23-29)}$.

Dúvidas vêm sendo levantadas na literatura, se os efeitos benéficos do procedimento de transplante autólogo em doenças auto-imunes não ocorreria em razão das altas doses de imunossupressão utilizadas no regime de condicionamento. Davis et al. ${ }^{(30)}$ utilizaram dois grupos de pacientes com artrite reumatóide severa, que receberam $20 \mathrm{mg} / \mathrm{m}^{2}$ $(\mathrm{n}=12)$ e $30 \mathrm{mg} / \mathrm{m}^{2}(\mathrm{n}=14)$ de fludarabina por 3 dias consecutivos mensalmente durante seis meses. Ambos os grupos apresentaram melhora clínica após 6 meses de tratamento, porém vários episódios infecciosos ocorreram. Viallard et al. ${ }^{(31)}$, em 1999, descreveram paciente com lúpus eritematoso sistêmico apresentando poliartrite irresponsiva a corticóides que melhorou substancialmente com o uso de $25 \mathrm{mg} / \mathrm{m}^{2}$ de fludarabina durante 5 dias num total de 6 ciclos da medicação. Profunda e prolongada supressão de sub-populações CD4+/ CD8+ são atingidas com fludarabina, um efeito de deleção química de linfócitos $\mathrm{T}$ patogênicos.

O uso de imunoablação seguido de transplante autólogo de medula óssea tem se mostrado um meio eficaz de tratar doenças auto-imunes, porém devemos salientar que este procedimento apresenta elevada taxa de mortalidade nos melhores centros, exigindo longos períodos de internação hospitalar e altos custos ${ }^{(17,32,33)}$. Seleção correta de pacientes (com critérios para identificar precocemente fatores adversos e para estabelecer as potenciais indicações), métodos de mobilização de células CD-34+, manipulação do enxerto (com remoção de células patogênicas), natureza e toxicidade do condicionamento (ajuste para cada distinta doença autoimune e complicações secundárias a longo prazo), questionamentos bioéticos em crianças e adultos, e recorrência precoce ou persistência da doença básica após o transplante são tópicos ainda não resolvidos e motivo de intenso debate na literatura mais atual ${ }^{(7,34-37)}$. No entanto, casos esporádicos e algumas séries tentam demonstrar que remissão total pode ser conseguida em indivíduos com doença resistente à terapêutica e severa a ponto de colocar em risco a vida dos pacientes. Assim, os potenciais riscos de uma terapia experimental seriam aceitáveis, com potenciais resultados muito favoráveis, mesmo em se tratando de crianças $^{(38)}$.

Uma alternativa a ser explorada seria utilizar quimioterapia não-mieloablativa, mas em doses maiores que as normalmente utilizadas por reumatologistas e sem suporte de CTH. Ciclofosfamida e fludarabina, da maneira como utilizamos no presente caso, são fármacos com efeito sinérgico e podem causar remissões sustentadas de pacientes com doenças auto-imunes quando utilizados isolada ou conjuntamente $^{(30,39,40)}$.

São necessários mais estudos utilizando esse grupo de drogas em esclerodermia para melhor avaliar sua eficácia, em estudos controlados com e sem suporte de células tronco hematopoéticas. 


\section{REFERÊNCIAS}

1. Canoso JJ: Systemic sclerosis (scleroderma) and related syndromes. In Rheumatology in primary care, JJ Canoso Editor, WB Saunders: Philadelphia. p. 104-14, 1997.

2. White B, Wigley FM, Steen VD: Systemic sclerosis and related disorders. In Primer on the Rheumatic Diseases, HR Schumacher Editor, Arthritis Foundation: Atlanta, 263-75, 1997.

3. Akesson A, Scheja A, Lundin A, Wollheim FA: Improved Pulmonary Function in Systemic Sclerosis After Treatment with Cyclophosphamide. Arthritis Rheum 37: 729-35, 1994.

4. Messner RP: The potential of bone marrow stem cell transplantation in the treatment of autoimmune diseases. J Rheumatol 24: 819-21, 1997.

5. Burt RK: BMT for severe autoimmune diseases: an idea whose time has come. Oncology (Huntingt) 11: 1001-14; 1017, discussion 1018-24, 1997.

6. Burt RK, Traynor AE, Pope R, et al: Treatment of autoimmune disease by intense immunosuppressive conditioning and autologous hematopoietic stem cell transplantation. Blood 92: 3505-14, 1998.

7. Snowden JA, Brooks PM: Hematopoietic stem cell transplantation in rheumatic diseases. Curr Opin Rheumatol 11: 167-72, 1999.

8. Tyndall A, Passweg J, Gratwohl A: Haemopoietic stem cell transplantation in the treatment of severe autoimmune diseases 2000. Ann Rheum Dis 60: 702-7, 2001.

9. Snowden JA, Brooks PM, Biggs JC: Haemopoietic stem cell transplantation for autoimmune diseases. Br J Haematol, 99: 9-22, 1997.

10. Lennard AL, Jackson GH: Stem cell transplantation. BMJ 321: 433-7, 2000.

11. Masi AT, et al: Preliminary criteria for the classification of systemic sclerosis (scleroderma). Arthritis and Rheum 23: 581-90, 1980.

12. Slaper-Cortenbach IC, Wijngaarden-du Bois MJ, De Vries-van Rossen A, et al: The depletion of $\mathrm{T}$ cells from haematopoietic stem cell transplants. Rheumatology 38: 751-4, 1999.

13. Bierings $\mathrm{M}$ : The role of T-cell depletion of autografts for autoimmune diseases. Rheumatology 38: 755-6, 1999.

14. Fassas A, Anagnostopoulos A, Kazis A, et al: Peripheral blood stem cell transplantation in the treatment of progressive multiple sclerosis: first results of a pilot study. Bone Marrow Transplant 20: 631-8, 1997.

15. Lim SH, Kell J, Al-Sabah A, Bashi W, Bailey-Wood R: Peripheral blood stem-cell transplantation for refractory autoimmune thrombocytopenic purpura. Lancet 349: 475, 1997.

16. Kahaleh MB, Sultany GL, Smith EA, Huffstutter JE, Loadholt CB, LeRoy EC: A modified scleroderma skin scoring method. Clin Exp Rheumatol 4: 367-9, 1986.

17. Jantunen E, Myllykangas-Luosujarvi R: Stem cell transplantation for treatment of severe autoimmune diseases: current status and future perspectives. Bone Marrow Transplant 25: 351-6, 2000.

18. Moore J, Tyndall A, Brooks P: Stem cells in the aetiopathogenesis and therapy of rheumatic disease. Best Pract Res Clin Rheumatol 15: 711-26, 2001.

19. Tyndall A, Black C, Finke J, et al: Treatment of systemic sclerosis with autologous haemopoietic stem cell transplantation. Lancet 349: 254, 1997.

20. Martini A, Maccario R, Ravelli A, et al: Marked and sustained improvement two years after autologous stem cell transplantation in a girl with systemic sclerosis. Arthritis Rheum 42: 807-11, 1999.

21. Breban M, Dougados M, Picard F, et al: Intensified-dose $\left(4 \mathrm{gm} / \mathrm{m}^{2}\right)$ cyclophosphamide and granulocyte colony-stimulating factor administration for hematopoietic stem cell mobilization in refractory rheumatoid arthritis. Arthritis Rheum 42: 2275-80, 1999.

22. Burt RK, Georganas C, Schroeder J, et al: Autologous hematopoietic stem cell transplantation in refractory rheumatoid arthritis: sustained response in two of four patients. Arthritis Rheum 42: 2281-5, 1999.

23. Marmont AM, Van Lint MT, Gualandi F, Bacigalupo A: Autologous marrow stem cell transplantation for severe systemic lupus erythematosus of long duration. Lupus 6: 545-8, 1997.

24. Musso M, Porretto F, Crescimanno A, et al: Autologous peripheral blood stem and progenitor (CD34+) cell transplantation for systemic lupus erythematosus complicated by Evans syndrome. Lupus 7: 492-4, 1998.

25. Fouillard L, Gorin NC, Laporte JP, Leon A, Brantus JF, Miossec P: Control of severe systemic lupus erythematosus after high-dose immunusuppressive therapy and transplantation of CD34+ purified autologous stem cells from peripheral blood. Lupus 8: 320-3, 1999.

26. Traynor A, Burt RK: Haematopoietic stem cell transplantation for active systemic lupus erythematosus. Rheumatology 38: 767-72, 1999.

27. Marmont AM: Intense immunosuppression and stem cell transplantation or rescue for severe systemic lupus erythematosus. Lupus 8: 256-7, 1999.

28. Traynor AE, Schroeder J, Rosa RM, et al: Treatment of severe systemic lupus erythematosus with high-dose chemotherapy and haemopoietic stem-cell transplantation: a phase I study. Lancet 356: 701-7, 2000.

29. Trysberg E, Lindgren I, Tarkowski A: Autologous stem cell transplantation in a case of treatment resistant central nervous system lupus. Ann Rheum Dis 59: 236-8, 2000.

30. Davis JC, Fessler BJ, Tassiulas IO, et al: High dose versus low dose fludarabine in the treatment of patients with severe refractory rheumatoid arthritis. J Rheumatol 25: 1694-704, 1998.

31. Viallard JF, Mercié P, Faure I, Pellegrin JL, Leng B: Successful treatment of lupus with fludarabine. Lupus 8: 767-9, 1999.

32. Tyndall A, Fassas A, Passweg J, et al: Autologous haematopoietic stem cell transplants for autoimmune disease--feasibility and transplant-related mortality. Autoimmune Disease and Lymphoma Working Parties of the European Group for Blood and Marrow Transplantation, the European League Against Rheumatism and the International Stem Cell Project for Autoimmune Disease. Bone Marrow Transplant 24: 729-34, 1999.

33. Binks M, Passweg JR, Furst D, et al: Phase I/II trial of autologous stem cell transplantation in systemic sclerosis: procedure related mortality and impact on skin disease. Ann Rheum Dis 60: 577-84, 2001.

34. Tyndall A: Immunoablation and haemopoietic stem cell transplantation for severe autoimmune disease with special reference to systemic lupus erythematosus. Lupus 10: 214-5, 2001.

35. Tyndall A, Gratwohl A: Blood and marrow stem cell transplants in auto-immune disease: a consensus report written on behalf of the European League against Rheumatism (EULAR) and the European Group for Blood and Marrow Transplantation (EBMT). Bone Marrow Transplant 19: 643-5, 1997.

36. Euler HH, Marmont AM, Bacigalupo A, et al: Early recurrence or persistence of autoimmune diseases after unmanipulated autologous stem cell transplantation. Blood 88: 3621-5, 1996.

37. Laxer RM, Harrison C: Bioethical issues in autologous stem cell transplantation in children and adults with arthritis. J Rheumatol 28: 2147-50, 2001.

38. Niethammer D, Kummerle-Deschner J, Dannecker GE: Side-effects of long-term immunosuppression versus morbidity in autologous stem cell rescue: striking the balance. Rheumatology 38: 747-50, 1999.

39. Frewin R, Turner D, Tighe M, Davies S, Rule S, Johnson S: Combination therapy with fludarabine and cyclophosphamide as salvage treatment in lymphoproliferative disorders. Br J Haematol 104: 612-3., 1999.

40. Mittal G, Balakrishna C, Mangat G, Joshi VR: 'Sustained remission' in a case of SLE following megadose cyclophosphamide. Lupus 8: 77-80, 1999. 